\title{
(6) OPEN ACCESS \\ The safety of vedolizumab for ulcerative colitis and Crohn's disease
}

\author{
Jean-Frédéric Colombel, ${ }^{1}$ Bruce E Sands, ${ }^{1}$ Paul Rutgeerts, ${ }^{2}$ William Sandborn, ${ }^{3}$ \\ Silvio Danese, ${ }^{4}$ Geert D'Haens, ${ }^{5}$ Remo Panaccione, ${ }^{6}$ Edward V Loftus $\mathrm{Jr}^{7}$ \\ Serap Sankoh, ${ }^{8}$ Irving Fox ${ }_{1}^{8}$ Asit Parikh, ${ }^{8}$ Catherine Milch, ${ }^{8}$ Brihad Abhyankar, ${ }^{9}$ \\ Brian G Feagan ${ }^{10}$
}

\begin{abstract}
Additional material is published online only. To view please visit the journal online (http://dx.doi.org/10.1136/ gutjnl-2015-311079).

For numbered affiliations see end of article.
\end{abstract}

\section{Correspondence to} Professor Jean-Frédéric Colombel, Division of Gastroenterology, Inflammatory Bowel Disease Center, Icahn School of Medicine, Mount Sinai Hospital, 17 East 102nd Street, 5th Floor, New York, NY 10029, USA; jean-frederic.colombel@ mssm.edu

Received 11 November 2015 Revised 14 January 2016 Accepted 15 January 2016 Published Online First 18 February 2016

\section{ABSTRACT}

Objective Vedolizumab is a gut-selective antibody to $\alpha_{4} \beta_{7}$ integrin for the treatment of ulcerative colitis (UC) and Crohn's disease (CD). We report an integrated summary of the safety of vedolizumab.

Design Safety data (May 2009-June 2013) from six trials of vedolizumab were integrated. Adverse events were evaluated in patients who received $\geq 1$ dose of vedolizumab or placebo and were reported as exposureadjusted incidence rates as the number of patients experiencing the event per 100 person-years (PYs) of exposure. Predictors of serious infection were assessed using a Cox proportional hazards model.

Results In total, 2830 patients had 4811 PYs of vedolizumab exposure (median exposure range, 11977 days). No increased risk of any infection or serious infection was associated with vedolizumab exposure. Serious clostridial infections, sepsis and tuberculosis were reported infrequently ( $\leq 0.6 \%$ of patients). No cases of progressive multifocal leucoencephalopathy were observed. Independent risk factors for serious infection in UC were prior failure of a tumour necrosis factor $\alpha$ antagonist (HR, 1.99; 95\% Cls 1.16 to $3.42 ; p=0.0122$ ) and narcotic analgesic use (HR, 2.68; $95 \% \mathrm{Cl} 1.57$ to 4.58; $p=0.0003)$, and in $C D$ were younger age ( $H R$, $0.97 ; 95 \% \mathrm{Cl} 0.95$ to $0.98 ; p<0.0001)$, corticosteroid ( $H R, 1.88 ; 95 \% \mathrm{Cl} 1.35$ to $2.63 ; p=0.0002$ ) or narcotic analgesic use (HR, 2.72; $95 \% \mathrm{Cl} 1.90$ to 3.89; $\mathrm{p}<0.0001)$. Investigator-defined infusion-related reactions were reported for $\leq 5 \%$ of patients in each study. Eighteen vedolizumab-exposed patients $(<1 \%)$ were diagnosed with a malignancy.

Conclusions Vedolizumab has a favourable safety profile with low incidence rates of serious infections, infusion-related reactions and malignancies over an extended treatment period.

Trial registration number NCT01177228, NCT00619489, NCT00783718, NCT00783692, NCT01224171, NCT00790933.

\section{Significance of this study}

What is already known on this subject?

- Vedolizumab is a monoclonal antibody that targets the $\alpha_{4} \beta_{7}$ integrin and selectively prevents the infiltration of leucocytes into the gastrointestinal submucosa.

- The efficacy and safety of vedolizumab in adults with IBD have been demonstrated in several clinical trials with follow-up to 1 year.

- Safety issues such as progressive multifocal leucoencephalopathy, infection and malignancy have been associated with other therapeutic monoclonal antibodies that are used to treat $U C$ and $C D$, such as tumour necrosis factor $\alpha$ antagonists and the integrin antagonist, natalizumab.

What are the new findings?

- Treatment with vedolizumab for up to 5 years in a population of over 2800 patients demonstrated a favourable safety profile.

- No cases of progressive multifocal leucoencephalopathy have been reported with vedolizumab to date.

- Vedolizumab is not associated with an increased risk of serious or opportunistic infections, and the rate of malignancy $(0.1 / 100$ person-years) is consistent with that observed in patients with IBD normally.

- Infusion-related reactions, enteric infections and autoimmune events occur infrequently with vedolizumab treatment.

How might it impact on clinical practice in the foreseeable future?

- A favourable benefit-risk profile makes vedolizumab a useful option for the long-term treatment of IBD.
CrossMark

To cite: Colombel J-F, Sands BE, Rutgeerts P, et al. Gut 2017:66:839-851.

\section{INTRODUCTION}

Leucocyte migration into inflamed intestinal tissue is regulated by specific molecular mechanisms. The $\alpha_{4} \beta_{7}$ integrin, a cell surface glycoprotein variably expressed on circulating $B$ lymphocytes and $\mathrm{T}$ lymphocytes, interacts with mucosal addressin cell adhesion molecule-1 on intestinal vasculature. ${ }^{1}$ Vedolizumab is a gut-selective, humanised monoclonal antibody targeting $\alpha_{4} \beta_{7}$ integrin. $^{2}{ }^{3}$ Clinical studies have demonstrated a positive benefit-risk profile of vedolizumab in adult patients with moderately to severely active ulcerative colitis (UC) or Crohn's disease (CD). ${ }^{4-6}$ No major differences in safety profiles were observed between placebo-treated and vedolizumab-treated patients. 
Nevertheless, important questions remain about the long-term safety (LTS) of vedolizumab in patients with inflammatory bowel disease (IBD). To address this issue, the cumulative LTS of vedolizumab was assessed in an integrated summary of data from six double-blind or open-label trials of patients with UC or CD. ${ }^{4-10}$

\section{METHODS}

\section{Patients}

Safety data were analysed from six clinical studies of vedolizumab (two phase 2 and four phase 3 studies) in patients with UC or CD that were conducted from 2 May 2007 through 27 June 2013 (figure 1 and online supplementary table S1). ${ }^{4-10}$ These trials have been described previously. ${ }^{4-10}$ The data reported here represent all phase 2 and phase 3 clinical studies in patients with IBD conducted to date with a bioequivalent formulation of the approved drug.

The overall safety population was defined as all patients $(\mathrm{N}=2932)$ who received one or more doses of study drug (vedolizumab or placebo) in at least one of the six studies (figure 1). The phase 3 safety population included patients from the phase 3 studies only $(\mathrm{N}=2884)$. Patients who received only placebo during GEMINI 1, GEMINI 2 or GEMINI $3(n=504)$ represented the placebo-exposed group; however, these patients may have received vedolizumab during GEMINI LTS. Integrated analyses were performed separately for each indication (UC or CD). For patients who participated in multiple studies, all safety data during vedolizumab exposure were combined. For GEMINI LTS, which is still ongoing, an interim data cut through 27 June 2013 was used.

\section{Safety and tolerability end points and analyses}

Safety and tolerability were evaluated in all patients in the safety population according to their exposure to study drug. Exposure was calculated using the number of days the patient received study drug, based on first and last dose dates. For patients not enrolled in the ongoing GEMINI LTS study at the data cut-off date, 16 weeks were added to the date of the last dose to account for the known duration of detectable vedolizumab serum concentrations. ${ }^{11}$ In phase 2 studies, a dose was defined as any amount of infusion, and in phase 3 studies, as $\geq 75 \%$ of the infusion by volume. Total vedolizumab exposure for a patient was calculated as the sum of exposures in all applicable studies. For patients who received only placebo, exposure to vedolizumab was calculated as 0 days.

Adverse events (AEs) were defined as any untoward medical occurrence in a patient administered a pharmaceutical product, which did not necessarily have a causal relationship with the treatment, and serious AEs (SAEs) were defined as any diagnosis of progressive multifocal leucoencephalopathy (PML) or any $\mathrm{AE}$ that was considered an important medical event, a congenital anomaly or life-threatening, or resulted in significant disability, hospitalisation or death. AEs and SAEs were classified by intensity (see online supplementary materials) and according to the Medical Dictionary for Regulatory Activities (MedDRA) ${ }^{12}$ V.14.0. Verbatim terms defined by MedDRA were used. Exposure-adjusted incidence rates, defined as the number of patients experiencing the event per 100 person-years (PYs) of exposure, were reported for AEs. Days of exposure were calculated from the $\mathrm{AE}$ onset date minus the date of first dose plus 1. PYs of exposure were calculated for the first occurrence of each $\mathrm{AE}$, and truncated after a patient experienced the $\mathrm{AE}$, although the patient continued to contribute PYs for different AEs experienced, if applicable. Thus, the total PYs of exposure could differ by AE. Patients randomised to placebo in a placebocontrolled study and then enrolled in an open-label study could contribute to events in either the placebo or vedolizumab group depending on when they experienced the AE. PYs were calculated accordingly for placebo or vedolizumab for each AE. Recognising the disproportionate PYs of follow-up for placebo compared with vedolizumab, statistical comparisons were not performed between the two groups. Calculation of 95\% CIs when the number of events was 0 followed the rule of 3 (ie, $(0$, $(3 /$ total PYs $) \times 100))$.

Infusion-related reactions (IRRs) were defined as AEs occurring on the day of or one calendar day after the infusion that were assessed by the investigator as infusion-related. In addition, blood samples for antivedolizumab antibody (AVA) assessment
Figure 1 Patient distribution within the overall safety population. The overall safety population includes all patients who received $\geq 1$ dose of study drug in the six studies. The phase 3 safety population includes patients from the phase 3 GEMINI studies only. Patients randomised to PBO in GEMINI 1, GEMINI 2 or GEMINI 3 and who enrolled into GEMINI LTS received open-label VDZ in that study. Thus, VDZ-exposed patients may also have been exposed to PBO. $\mathrm{CD}$, Crohn's disease; LTS, long-term safety; PBO, placebo; PD, pharmacodynamics; $P K$, pharmacokinetics; UC, ulcerative colitis; VDZ, vedolizumab. ${ }^{a}$ One enrolled patient randomised to VDZ was not dosed. ${ }^{b}$ Includes 38 and 421 VDZ-naïve patients who enrolled directly into C13004 or GEMINI LTS, respectively. 'Includes data collected from 22 May 2009 to 27 June 2013.

PBO-controlled Studies

Open-label Studies

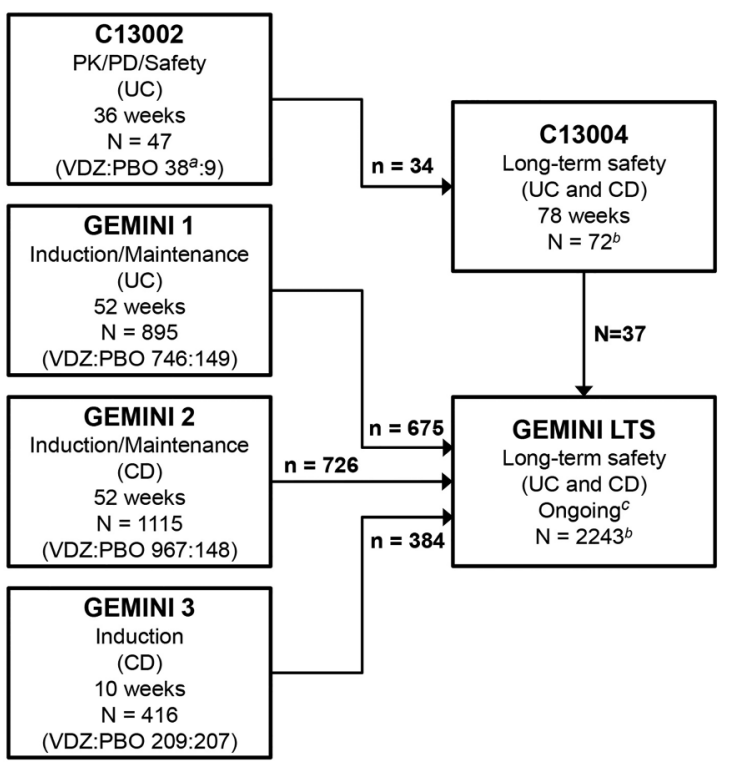

Integrated safety population $\mathbf{N}=\mathbf{2 9 3 2}$ patients $n=2830 \mathrm{VDZ}$-exposed patients $n=513$ PBO-exposed patients

Phase 3 safety population $\mathbf{N}=\mathbf{2 8 8 4}$ patients $n=2789$ VDZ-exposed patients $n=504$ PBO-exposed patients 
were collected within $30 \mathrm{~min}$ before dosing in the phase 3 studies and within $2 \mathrm{~h}$ in the phase 2 studies. Immunogenicity was determined as described elsewhere. ${ }^{13}$

\section{Predictors of serious infections}

A Cox proportional hazards model with time-dependent covariates was used to determine the relative contribution (HRs and 95\% CIs) of different factors to the occurrence of serious infections in the phase 3 safety population, which included patients in both treatment arms. Predictors were analysed in the UC and $\mathrm{CD}$ populations alone and combined. Factors assessed were age, sex, disease duration, baseline disease activity, prior history of tumour necrosis factor $\alpha$ antagonist (anti-TNF) failure, baseline use of immunosuppressives, on-study use of narcotic analgesics (all opioids) or on-study use of corticosteroids. Patients were considered corticosteroid users in this model if they received corticosteroids within 30 days before the infection date. When patients with UC and CD were combined, a common disease activity index was created to measure the contribution of baseline disease activity (see online supplementary table S2). Vedolizumab treatment was not included as a covariate because nearly all patients analysed were exposed to vedolizumab at one point $(97 \%)$, invariably resulting in significantly lower HRs for serious infection.

\section{Progressive multifocal leucoencephalopathy screening and hypothetical estimation of risk}

Patients were screened for symptoms of PML with an algorithm for PML risk minimisation as described elsewhere. ${ }^{14}$ Briefly, when new neurological symptoms were reported, patients were referred to a dedicated study neurologist co-investigator for further evaluation, and when indicated, the case was reviewed by an independent adjudication committee (IAC) composed of academic neurologists, neuroradiologists and a virologist (see online supplementary materials).

The likelihood of observing any PML cases with vedolizumab was calculated assuming that the PML incidence rate was similar to that of natalizumab and that the number of expected cases would follow a Poisson distribution (see online supplementary materials).

\section{RESULTS}

\section{Patient baseline characteristics and treatment exposure}

The overall safety population included 2932 patients who enrolled in the six studies (figure 1). Of these, 2830 patients were exposed to one or more doses of vedolizumab, contributing a total of 4811 PYs of vedolizumab exposure (see online supplementary figure S1). The phase 3 safety population was composed of 2884 patients, of whom 504 patients received placebo (figure 1), contributing a total of 214 PYs of placebo exposure (see online supplementary figure S1). Placebo-treated patients from GEMINI 1, GEMINI 2 and GEMINI 3 who enrolled in GEMINI LTS received open-label vedolizumab and therefore also contributed to PYs of vedolizumab exposure. Thus, most patients (97\%) in the phase 3 safety population received one or more doses of vedolizumab (table 1). The median vedolizumab exposure in the phase 3 safety population was 378 days (range, 1-1977) and 338 days (range, 1-1927) for patients with UC and CD, respectively (table 2). In the overall safety population, the number of PYs of vedolizumab exposure was $>22$ times that for placebo.

Baseline characteristics are reported for the phase 3 safety population by disease and separately for the 504 patients who received placebo (table 1). Placebo-exposed patients were similar to the overall population with respect to age, sex, disease duration, concomitant medication use, narcotic analgesic use, smoking status and prior anti-TNF failure history.

\section{Adverse events and serious adverse events}

Exposure-adjusted incidence rates for all AEs and all SAEs were lower with vedolizumab exposure than with placebo. In the overall safety population, 247.8 (95\% CI 229.8 to 265.8 ) and 20.0 (95\% CI 18.5 to 21.5) vedolizumab-exposed patients experienced an $\mathrm{AE}$ or SAE, respectively, per $100 \mathrm{PYs}$ of follow-up compared with 419.4 (95\% CI 359.3 to 479.5 ) and 28.3 (95\% CI 20.6 to 35.9 ) patients receiving placebo (table 3 ). The majority of SAEs in UC and CD populations and with

Table 1 Baseline characteristics of the phase 3 safety population

\begin{tabular}{|c|c|c|c|c|}
\hline Characteristic & UC $(n=1114)$ & $C D(n=1770)$ & UC and $C D^{*}(\mathrm{~N}=2884)$ & UC and CD Placebot $(n=504)$ \\
\hline Received $\geq 1$ dose of vedolizumab, $n(\%)$ & $1077(97)$ & $1712(97)$ & $2789(97)$ & $409(81)$ \\
\hline Age, mean years $\pm S D$ & $40.4 \pm 13.4$ & $36.8 \pm 12.5$ & $38.2 \pm 13.0$ & $38.8 \pm 13.1$ \\
\hline Sex, female, n (\%) & $462(42)$ & $974(55)$ & $1436(50)$ & $254(50)$ \\
\hline \multicolumn{5}{|l|}{ Disease duration, $\mathrm{n}(\%) \ddagger$} \\
\hline$<7$ years & $679(61)$ & $833(47)$ & $1512(52)$ & $269(53)$ \\
\hline$\geq 7$ years & $404(36)$ & $929(53)$ & $1333(46)$ & $235(47)$ \\
\hline Mean years $\pm S D$ & $7.2 \pm 6.8$ & $9.5 \pm 8.1$ & $8.7 \pm 7.7$ & $8.6 \pm 7.8$ \\
\hline \multicolumn{5}{|l|}{ Disease activity, mean score $\pm S D$} \\
\hline Partial Mayo score & $5.9 \pm 1.8$ & N/A & $5.9 \pm 1.8$ & $6.1 \pm 1.5$ \\
\hline $\mathrm{HBI}$ score & N/A & $11.0 \pm 3.6$ & $11.0 \pm 3.6$ & $10.7 \pm 3.4$ \\
\hline Prior anti-TNF therapy failure, $\mathrm{n}(\%)$ & $483(45)$ & $1127(64)$ & $1610(57)$ & $289(57)$ \\
\hline \multicolumn{5}{|l|}{ Concomitant medications, n (\%) } \\
\hline Corticosteroid & $591(53)$ & $925(52)$ & $1516(53)$ & $263(52)$ \\
\hline Immunosuppressive & $359(32)$ & $558(32)$ & $917(32)$ & $164(33)$ \\
\hline Narcotic analgesic use, n (\%) & $102(9)$ & $310(18)$ & $412(14)$ & $70(14)$ \\
\hline Current smoker, n (\%) & $60(5)$ & $469(27)$ & $529(18)$ & $103(20)$ \\
\hline
\end{tabular}

*Phase 3 safety population includes patients from studies GEMINI 1, GEMINI 2, GEMINI 3 and GEMINI LTS. Patients in study C13004 who rolled over to GEMINI LTS are included. tIncludes patients who were randomised to placebo in studies GEMINI 1, GEMINI 2 and GEMINI 3.

$\neq$ Does not include patients who began treatment in study C13002 or C13004.

anti-TNF, tumour necrosis factor $\alpha$ antagonist; CD, Crohn's disease; HBI, Harvey-Bradshaw index; LTS, long-term safety; N/A, not applicable; SD, standard deviation; UC, ulcerative colitis. 
Table 2 Exposure to study drug in the phase 3 safety population

\begin{tabular}{|c|c|c|c|}
\hline & UC $(n=1114)$ & $C D(n=1770)$ & $\begin{array}{l}\text { UC and } \mathrm{CD}^{*} \\
(\mathrm{~N}=2884)\end{array}$ \\
\hline \multicolumn{4}{|c|}{ Patients exposed to vedolizumab, $n(\%)$} \\
\hline$\geq 1$ dose & $1077(97)$ & $1712(97)$ & $2789(97)$ \\
\hline$\geq 6$ months & $837(75)$ & $1163(66)$ & $2000(69)$ \\
\hline$\geq 12$ months & $574(52)$ & $827(47)$ & $1401(49)$ \\
\hline$\geq 18$ months & $473(42)$ & $677(38)$ & $1150(40)$ \\
\hline$\geq 24$ months & $428(38)$ & $478(27)$ & $906(31)$ \\
\hline$\geq 36$ months & $198(18)$ & 209 (12) & 407 (14) \\
\hline$\geq 48$ months & $30(3)$ & $10(1)$ & $40(1)$ \\
\hline \multicolumn{4}{|c|}{ Extent of vedolizumab exposure, days } \\
\hline \multirow[t]{2}{*}{ Median (Min, Max) } & $378(1,1977)$ & $338(1,1927)$ & $365(1,1977)$ \\
\hline & UC & $C D$ & \\
\hline $\begin{array}{l}\text { Extent of placebo } \\
\text { exposure, days }\end{array}$ & $\begin{array}{l}\text { GEMINI } 1 \\
(n=149)\end{array}$ & $\begin{array}{l}\text { GEMINI } 2 \\
(n=148)\end{array}$ & $\begin{array}{l}\text { GEMINI } 3 \\
(\mathrm{n}=207)\end{array}$ \\
\hline Median (Min, Max) & $99(1,362)$ & $106(1,372)$ & $42(1,72)$ \\
\hline
\end{tabular}

either treatment were gastrointestinal (GI) events and infections. Prolonged exposure to vedolizumab did not increase the frequency of AEs or SAEs, including GI SAEs or serious infections (see online supplementary table S3 and figure S2).

Uncommon but important non-infectious events associated with anti-TNFs, such as congestive heart failure exacerbation or demyelination, were not seen with vedolizumab. A single case of demyelination occurred in a placebo-treated patient. Overall, 15 patients exposed to vedolizumab developed psoriatic conditions, with a rate of $0.3 / 100$ PYs (95\% CI 0.2 to 0.5 ), and no placebo-exposed patients.

\section{Infections and serious infections}

In the overall safety population, the exposure-adjusted incidence rates of any infection were lower among patients receiving vedolizumab (63.5/100 PYs; 95\% CI 59.6 to 67.3) than placebo (82.9/100 PYs; 95\% CI 68.3 to 97.5) (table 4). Most infections were mild to moderate in severity and responded to standard treatment while patients had continued exposure to vedolizumab. The exposure-adjusted incidence rates of serious infections were similar for vedolizumab and placebo (table 5). Few patients $(<1 \%)$ discontinued treatment because of infection.

Upper respiratory tract infections accounted for approximately half or more of the total infections reported (table 4). The incidence rates of upper respiratory tract infections were 28.6/100 PYs with vedolizumab and 34.7/100 PYs with placebo. Abdominal and GI infections and lower respiratory tract and lung infections occurred with similar incidence rates for vedolizumab and placebo. All other infections with vedolizumab occurred with an incidence rate of $<5 / 100$ PYs (table 4 ).

Serious infections of interest, including clostridial infections, sepsis, tuberculosis (TB) and Listeria meningitis were reported for between 1 and 15 patients $(\leq 0.6 \%)$ (table 5$)$. All clostridial infections occurred in vedolizumab-exposed patients (tables 4 and 5). Of the four reports of TB, three were diagnoses of pulmonary TB in patients (one UC and two CD) enrolled in GEMINI LTS who had negative screenings for TB at enrolment and were taking concomitant immunosuppressives. All cases were considered to be primary infections with no extrapulmonary manifestations. In addition, latent TB was diagnosed in one patient with CD who was previously treated with immunosuppressives. All cases of active TB occurred in hyperendemic jurisdictions. One vedolizumab-treated patient taking concomitant methylprednisolone and azathioprine developed Listeria meningitis; the infection resolved with treatment.

The higher rate of GI infections in vedolizumab patients was largely due to gastroenteritis. Rates of gastroenteritis with vedolizumab and placebo, respectively, were 3.7/100 PYs and 0/100 PYs in patients with UC and 4.2/100 PYs and 2.3/100 PYs in patients with CD. As expected, abscesses were prevalently observed in the CD population. Rates of abscess and serious abscess were 4.8/100 PYs and 2.4/100 PYs, respectively, in vedolizumab-treated patients with $\mathrm{CD}$, the majority being anal, rectal or perirectal (tables 4 and 5). Notably, abscess rates were higher with placebo than vedolizumab (table 4).

\section{Progressive multifocal leucoencephalopathy}

Unexplained neurological symptoms were experienced by $10 \%$ of patients in the overall safety population. Serial evaluation of these 290 patients revealed that 64 had evidence of neurological abnormalities. None of the 86 cases referred to the IAC were identified as PML after extensive review. No confirmed PML cases have been documented during 2 years of telephone follow-up.

Across all vedolizumab clinical studies, 3326 participants were exposed to vedolizumab for $\leq 24$ months, and 906 participants were exposed to vedolizumab for $>24$ months. Approximately $80 \%$ of patients in both subgroups had prior immunosuppressive exposure. Assuming 50\% seropositivity for anti-John Cunningham virus (JCV) antibodies, modelling the expected number of cases as a Poisson distribution using natalizumab risk estimates suggests that an average of six to seven cases would have occurred in the current vedolizumab safety population had the risk of PML been similar to that of natalizumab. The probability of observing 0 PML cases in this context is exceedingly low $(\mathrm{p}<0.0012)$ (see online supplementary figure S3).

\section{Risk factors for serious infection}

Risk factors for serious infection were assessed with a Cox proportional hazards model (table 6). Independent risk factors for serious infection in patients with UC were prior anti-TNF failure (HR, $1.99 ; 95 \%$ CI 1.16 to $3.42 ; \mathrm{p}=0.0122)$ and concomitant narcotic analgesic use (HR, 2.68; 95\% CI 1.57 to $4.58 ; \mathrm{p}=0.0003)$. For patients with $\mathrm{CD}$, younger age $(\mathrm{HR}$, $0.97 ; 95 \%$ CI 0.95 to $0.98 ; \mathrm{p}<0.0001)$, concomitant corticosteroid use (HR, $1.88 ; 95 \%$ CI 1.35 to $2.63 ; \mathrm{p}=0.0002)$ and concomitant narcotic analgesic use (HR, 2.72; 95\% CI 1.90 to $3.89 ; \mathrm{p}<0.0001)$ were independent risk factors for serious infection. The same risk factors identified for patients with CD alone were observed in the combined UC and $\mathrm{CD}$ population (younger age (HR, 0.98; 95\% CI 0.97 to $1.00 ; \mathrm{p}=0.0003$ ), concomitant corticosteroid use (HR, 1.72; 95\% CI 1.30 to $2.28 ; \mathrm{p}=0.0002)$ and concomitant narcotic analgesic use (HR, 2.76; 95\% CI 2.06 to $3.72 ; \mathrm{p}<0.0001)$ ). Baseline disease activity was not associated with a greater risk of serious infection (table 6).

\section{Immunogenicity}

AVAs were detected in 56 of 1434 patients (4\%) from GEMINI 1 and GEMINI 2 treated with vedolizumab continuously for up to 52 weeks; of these 56 patients, 9 were persistently positive (defined by AVA-positive samples on two or more consecutive visits), and 33 developed neutralising antibodies. During follow-up, among 320 patients who had data available from a 


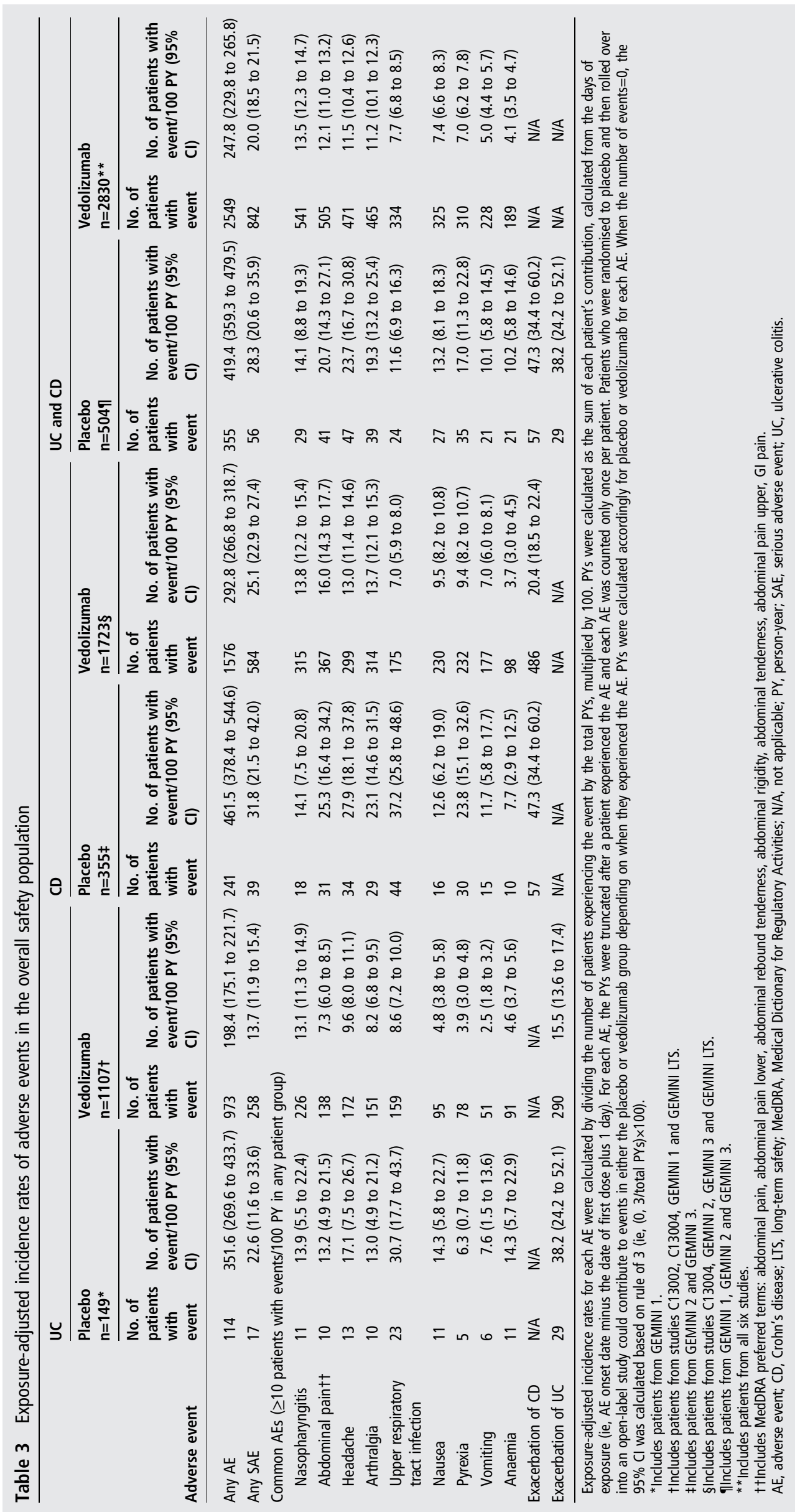




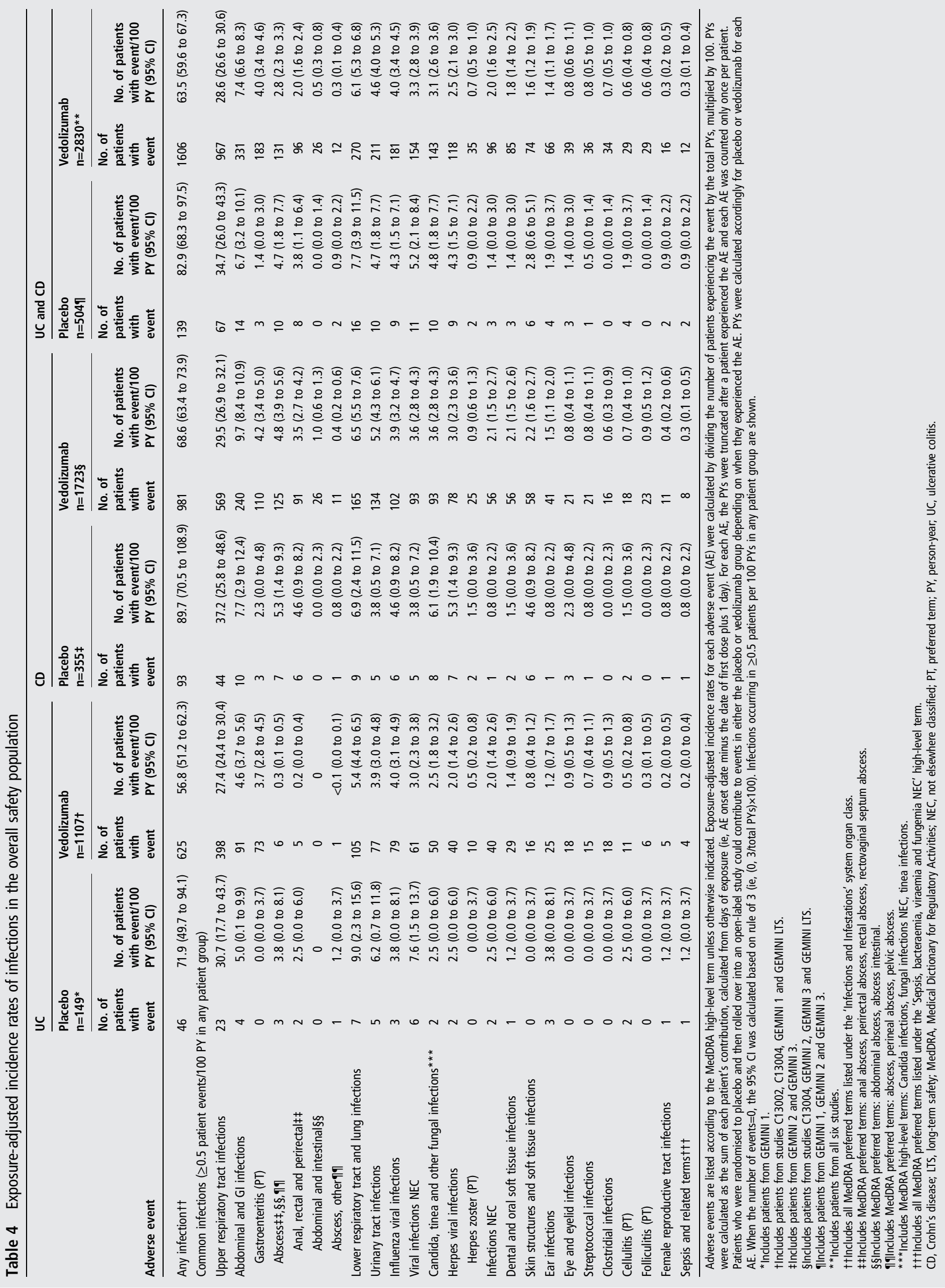




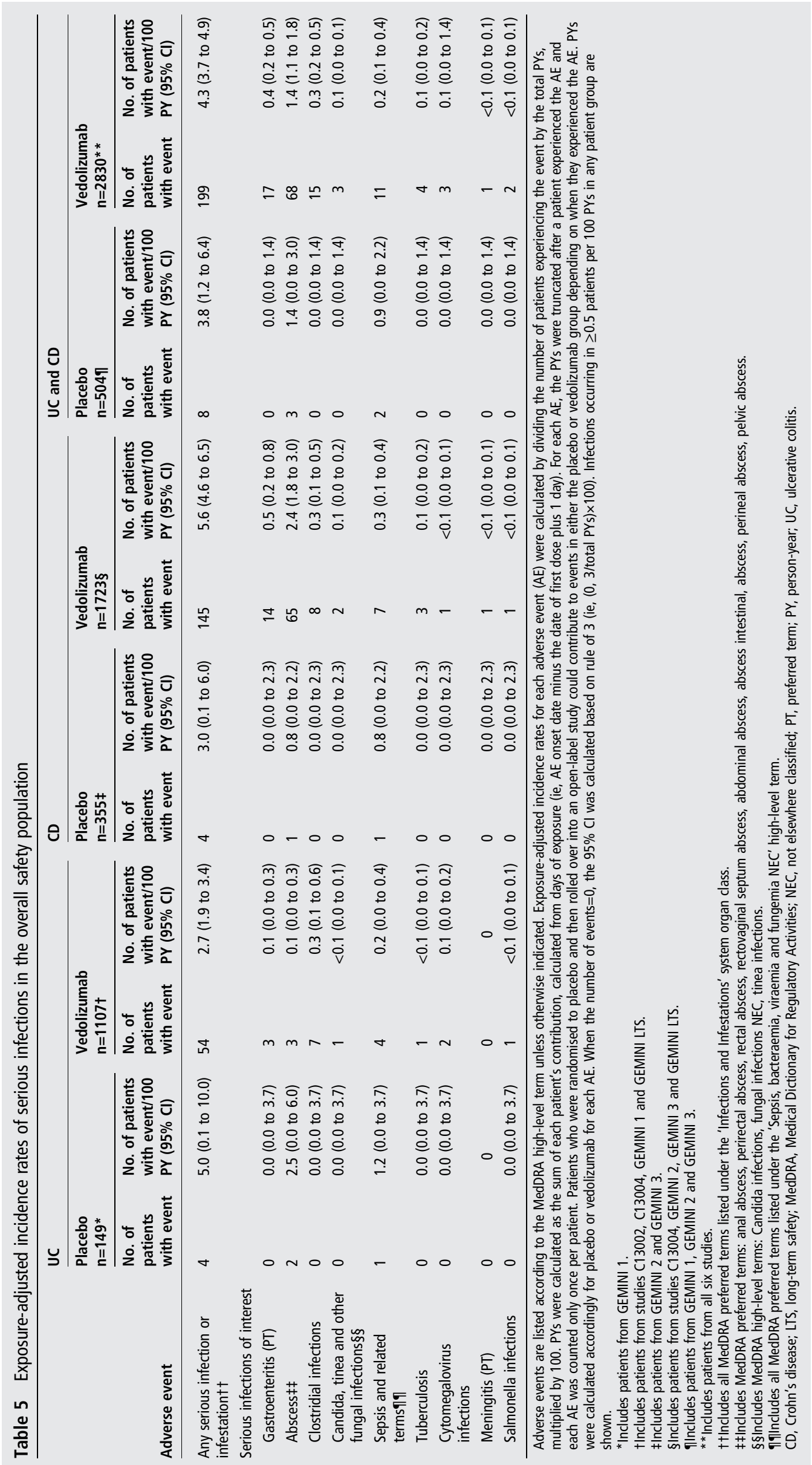


Table 6 Predictors of serious infections in the phase 3 safety population

\begin{tabular}{|c|c|c|c|c|}
\hline \multirow[b]{2}{*}{ Variable* } & \multirow[b]{2}{*}{ Patientst } & \multirow[b]{2}{*}{ Serious infections } & \multicolumn{2}{|l|}{ Adjusted results } \\
\hline & & & $\mathrm{HR}(95 \% \mathrm{CI})$ & p Value \\
\hline UC phase 3 population & $n=1114$ & $\mathrm{n}=59$ & & \\
\hline Age, mean years $\pm S D$ & $40.4 \pm 13.4$ & $42.1 \pm 15.1$ & $1.00(0.98$ to 1.02$)$ & 0.98 \\
\hline Sex, female, $n(\%)$ & $462(42)$ & $28(48)$ & $1.10(0.65$ to 1.85$)$ & 0.72 \\
\hline Disease duration $\geq 7$ years, $\mathrm{n}(\%)$ & $404(36)$ & $22(37)$ & $0.94(0.54$ to 1.63$)$ & 0.82 \\
\hline Prior anti-TNF therapy failure, $\mathrm{n}(\%)$ & $483(45)$ & $33(56)$ & 1.99 (1.16 to 3.42$)$ & 0.0122 \\
\hline Baseline disease activity, mean Mayo score \pm SD & $5.9 \pm 1.8$ & $5.9 \pm 1.6$ & $0.96(0.82$ to 1.12$)$ & 0.56 \\
\hline On-study narcotic use, n (\%) & $323(29)$ & $34(58)$ & 2.68 (1.57 to 4.58$)$ & 0.0003 \\
\hline On-study corticosteroid use, n (\%) & $430(39)$ & $22(37)$ & $1.58(0.92$ to 2.71$)$ & 0.10 \\
\hline Baseline immunosuppressive use, $\mathrm{n}(\%)$ & $359(32)$ & $24(41)$ & $1.68(0.98$ to 2.87$)$ & 0.06 \\
\hline Vedolizumab treatment, n (\%)‡ & $1077(97)$ & $56(95)$ & N/A & $\mathrm{N} / \mathrm{A}$ \\
\hline CD phase 3 population & $\mathrm{n}=1770$ & $\mathrm{n}=148$ & & \\
\hline Age, mean years $\pm S D$ & $36.8 \pm 12.5$ & $34.6 \pm 11.8$ & 0.97 (0.95 to 0.98$)$ & $<0.0001$ \\
\hline Sex, female, $\mathrm{n}(\%)$ & $974(55)$ & $88(60)$ & $1.30(0.93$ to 1.82$)$ & 0.12 \\
\hline Disease duration $\geq 7$ years, $\mathrm{n}(\%)$ & $929(53)$ & $84(57)$ & $1.18(0.82$ to 1.68$)$ & 0.37 \\
\hline Prior anti-TNF therapy failure, $\mathrm{n}(\%)$ & $1127(64)$ & $95(65)$ & $0.82(0.57$ to 1.19$)$ & 0.30 \\
\hline Baseline disease activity, mean $\mathrm{HBI}$ score \pm SD & $11.0 \pm 3.6$ & $10.9 \pm 3.4$ & $1.01(0.96$ to 1.06$)$ & 0.70 \\
\hline On-study narcotic use, $\mathrm{n}(\%)$ & $731(41)$ & $96(65)$ & 2.72 (1.90 to 3.89$)$ & $<0.0001$ \\
\hline On-study corticosteroid use, n (\%) & $708(40)$ & $66(45)$ & 1.88 (1.35 to 2.63$)$ & 0.0002 \\
\hline Baseline immunosuppressive use, $n(\%)$ & $558(32)$ & $41(28)$ & $0.78(0.54$ to 1.13$)$ & 0.19 \\
\hline Vedolizumab treatment, $\mathrm{n}(\%) \ddagger$ & $1712(97)$ & $144(97)$ & $\mathrm{N} / \mathrm{A}$ & N/A \\
\hline Combined phase 3 population & $\mathrm{N}=2884$ & $\mathrm{n}=207$ & & \\
\hline Age, mean years $\pm S D$ & $38.2 \pm 13.0$ & $36.8 \pm 13.2$ & $0.98(0.97$ to 1.00$)$ & 0.0003 \\
\hline Sex, female, n (\%) & $1436(50)$ & $116(56)$ & $1.28(0.97$ to 1.69$)$ & 0.09 \\
\hline Disease duration $\geq 7$ years, $\mathrm{n}(\%)$ & $1333(46)$ & $106(51)$ & $1.12(0.84$ to 1.50$)$ & 0.44 \\
\hline Prior anti-TNF therapy failure, $\mathrm{n}(\%)$ & $1610(57)$ & $128(62)$ & $1.19(0.88$ to 1.62$)$ & 0.26 \\
\hline Baseline disease activity, mean score \pm SD $\S$ & $5.7 \pm 1.8$ & $5.6 \pm 1.7$ & $0.98(0.91$ to 1.07$)$ & 0.68 \\
\hline On-study narcotic use, n (\%) & $1054(37)$ & $130(63)$ & 2.76 (2.06 to 3.72$)$ & $<0.0001$ \\
\hline On-study corticosteroid use, n (\%) & $1138(40)$ & $88(43)$ & $1.72(1.30$ to 2.28$)$ & 0.0002 \\
\hline Baseline immunosuppressive use, n (\%) & $917(32)$ & $65(31)$ & $0.97(0.72$ to 1.31$)$ & 0.86 \\
\hline Vedolizumab treatment, n (\%)‡ & $2789(97)$ & $200(97)$ & $\mathrm{N} / \mathrm{A}$ & $\mathrm{N} / \mathrm{A}$ \\
\hline
\end{tabular}

final safety visit, $10 \%$ had positive test results for AVAs 16 weeks after last dose. The coadministration of immunosuppressives at baseline of the studies decreased the AVA positivity rate by $1 \%$, from $4 \%$ to $3 \%$. However, these values were determined when patients had a high level of drug present in the serum, which interferes with detection of AVAs with the assay used. ${ }^{13}$ Among patients who received vedolizumab during the induction phase and placebo during the maintenance phase, a greater percentage of patients were AVA-positive (18\%) without concomitant immunosuppressive use at baseline compared with those with baseline immunosuppressive use $(3 \%) .{ }^{15}$ Based on data from the ongoing GEMINI LTS study, the immunogenicity rate did not appear to increase over time.

\section{Infusion-related reactions}

In each of the six studies included here, $\leq 5 \%$ of patients receiving vedolizumab experienced an IRR as defined by the investigator. In the 52-week phase 3 studies, IRRs with vedolizumab and placebo, respectively, were reported for $28(5 \%)$ and 1 $(<1 \%)$ patients with UC and $33(4 \%)$ and $8(5 \%)$ patients with CD. ${ }^{4}{ }^{16}$ An additional four $(2 \%)$ and two $(<1 \%)$ patients with CD experienced an IRR with vedolizumab and placebo, respectively, in the 10 -week GEMINI 3 study. $^{6}$ In the phase 2 studies, IRRs were reported for two patients (one UC, one CD).

Cumulative data for the 2243 patients enrolled in GEMINI LTS showed that 87 patients (4\%) had an IRR. The most frequently reported IRRs were nausea (14 patients) and headache (10 patients). All other events occurred in $<10$ patients $(<1 \%)$. Twelve patients $(<1 \%)$ had the infusion interrupted or received an incomplete dose because of an IRR.

Overall, the majority of IRRs were mild or moderate in intensity, and rarely resulted in discontinuation of study drug. Among the 2830 vedolizumab-exposed patients, three IRRs were considered serious and resolved following standard care (see patient narratives in online supplementary materials). With 52 weeks of vedolizumab exposure in GEMINI 1 and GEMINI 2, three of the 61 patients (5\%) who experienced an IRR were AVA-positive and three of the 56 patients (5\%) who were AVA-positive experienced an IRR.

\section{Malignancies}

During the phase 3 studies, all malignancies occurred in 18 patients receiving vedolizumab-six patients in the placebo- 
Table 7 Malignancies reported for the overall safety population

\begin{tabular}{|c|c|c|c|c|}
\hline Indication & $\begin{array}{l}\text { Age/ } \\
\text { sex }\end{array}$ & $\begin{array}{l}\text { Vedolizumab } \\
\text { doses* }\end{array}$ & Malignancy (PT) & Prior therapy \\
\hline \multicolumn{5}{|c|}{ Placebo-controlled studies } \\
\hline UC & $70.7 / \mathrm{F}$ & 0 & $\begin{array}{l}\text { Basal cell carcinoma } \\
\text { Squamous cell } \\
\text { carcinoma }\end{array}$ & $\begin{array}{l}\text { AZA, 6MP, CS, } \\
\text { GLM }\end{array}$ \\
\hline UC & $40.5 / \mathrm{M}$ & 2 & $\begin{array}{l}\text { Transitional cell } \\
\text { carcinoma }\end{array}$ & AZA, 6MP, CS† \\
\hline UC & 73.7/M & 2 & Colon cancer & AZA, 6MP, CS \\
\hline UC & $32.7 / \mathrm{M}$ & 7 & Colon cancer & $\begin{array}{l}\text { AZAt, 6MP, } \\
\text { IFX, CSt }\end{array}$ \\
\hline$C D$ & $45.2 / \mathrm{F}$ & 2 & Breast cancer & AZA, 6MP, CS† \\
\hline$C D$ & $52.1 / \mathrm{F}$ & 10 & $\begin{array}{l}\text { Squamous cell } \\
\text { carcinoma }\end{array}$ & $\begin{array}{l}\text { ADA, IFX, AZA, } \\
\text { 6MP, MTX, CS }\end{array}$ \\
\hline$C D$ & $20.7 / \mathrm{F}$ & 13 & $\begin{array}{l}\text { Carcinoid tumour of } \\
\text { the appendix }\end{array}$ & $\begin{array}{l}\text { ADA, IFX, AZA, } \\
6 \mathrm{MP}, \mathrm{CS}\end{array}$ \\
\hline \multicolumn{5}{|c|}{ Open-label studies } \\
\hline UC & $47.4 / \mathrm{M}$ & 2 & Malignant melanoma & $\begin{array}{l}\text { IFX, AZAt, } \\
6 \mathrm{MP}, \mathrm{MTX}, \mathrm{CS}\end{array}$ \\
\hline UC & $75.3 / F$ & 3 & $\begin{array}{l}\text { Lung neoplasm } \\
\text { malignant }\end{array}$ & $\begin{array}{l}\text { AZA, 6MP, IFX, } \\
\text { CS }\end{array}$ \\
\hline UC & 63.5/M & 6 & Breast cancer in situ & $\begin{array}{l}\text { MTX, IFX, AZA, } \\
\text { CS }\end{array}$ \\
\hline UC & 44.1/M & 8 & $\begin{array}{l}\text { Metastases to } \\
\text { peritoneum }\end{array}$ & IFX, CS, AZA \\
\hline UC & $70.2 / \mathrm{M}$ & 9 & Malignant melanoma & $\begin{array}{l}\text { IFX, AZA, 6MP, } \\
\text { CS }\end{array}$ \\
\hline UC & $50.4 / \mathrm{M}$ & 29 & Renal cancer & CS \\
\hline$C D$ & $69 / F$ & 3 & $\begin{array}{l}\text { Lung neoplasm } \\
\text { malignant (hepatic } \\
\text { neoplasm malignant) }\end{array}$ & $\begin{array}{l}\text { MTX, ADA, IFX, } \\
\text { AZA, 6MP, CSt }\end{array}$ \\
\hline$C D$ & $45.5 / \mathrm{F}$ & 8 & Colon cancer & $\begin{array}{l}\text { IFX, AZA, 6MP, } \\
\text { CSt }\end{array}$ \\
\hline$C D$ & $46.8 / \mathrm{M}$ & 12 & Basal cell carcinoma & $\begin{array}{l}\text { IFX, ADA, AZA, } \\
\text { 6MP, MTX, CS }\end{array}$ \\
\hline$C D$ & 42.9/M & 21 & B cell lymphoma & $\begin{array}{l}\text { AZAt, } 6 \mathrm{MP}, \\
\text { IFX, CSt, } \\
\text { rituximabt }\end{array}$ \\
\hline$C D$ & 49.7/M & 37 & $\begin{array}{l}\text { Squamous cell } \\
\text { carcinoma }\end{array}$ & AZAt, 6MP, CS \\
\hline$C D$ & $51.1 / F$ & 41 & $\begin{array}{l}\text { Hepatic neoplasm } \\
\text { malignant }\end{array}$ & $\begin{array}{l}\text { ADA, AZA, } \\
6 \mathrm{MP}, \mathrm{CS}\end{array}$ \\
\hline
\end{tabular}

*Infusions before or on the first occurrence of selected adverse events. For patients who participated in multiple clinical studies, all doses of vedolizumab were counted. tContinued use on study.

6MP, mercaptopurine; ADA, adalimumab; AZA, azathioprine; $C D$, Crohn's disease; $C S$, corticosteroids; GLM, golimumab; IFX, infliximab; MTX, methotrexate; PT, preferred term; UC, ulcerative colitis.

controlled trials and 12 patients receiving open-label vedolizumab (table 7) -and one patient receiving placebo. Among vedolizumab-exposed patients, GI malignancies were most frequent. Two of the patients with colon cancer had colonoscopies within 1 month of diagnosis, which ultimately confirmed the disease. Five patients had dermatological malignancies, all of which were reported as resolved. Malignant neoplasms reported following $\geq 20$ infusions of vedolizumab included renal cancer, B cell lymphoma, squamous cell carcinoma and hepatocellular carcinoma in one patient each (table 7). Risk factors and treatment outcomes for patients with malignancies are summarised in online supplementary table S4.

\section{GI adverse events}

In the overall safety population, the incidence rate of any GI $\mathrm{AE}$ with placebo (114.5/100 PYs; 95\% CI 95.8 to 133.1) was nearly twice as high as with vedolizumab (59.8/100 PYs; 95\%
CI 56.2 to 63.4) (table 8). The rate of stenosis was similar in patients with $C D$ irrespective of treatment. The rate of fistulae in patients with CD was lower with vedolizumab (4.6/100 PYs; $95 \%$ CI 3.8 to 5.5$)$ than with placebo (10.0/100 PYs; 95\% CI 4.5 to 15.5$)$.

\section{Hepatobiliary events}

Across the six studies, 23 hepatobiliary events were reported in 22 vedolizumab-treated patients; no cases were observed among placebo-exposed patients (see online supplementary table S5). Nine patients had hepatic steatosis with an incidence rate of 0.2 / 100 PYs; all other individual incidence rates were $\leq 0.1 / 100$ PYs. Patients exposed to vedolizumab or placebo had similar low exposure-adjusted incidence rates of liver enzyme abnormalities (vedolizumab, 2.1/100 PYs vs placebo, 2.8/100 PYs) (see online supplementary table S6). No liver enzyme abnormalities led to study drug discontinuation. Five of the hepatic events were considered serious (see patient narratives in online supplementary materials). One patient was later diagnosed with subacute cutaneous lupus erythematosus. All patients were treated accordingly with resolution or near resolution of the liver abnormality.

\section{Deaths}

A total of 13 deaths were reported for the vedolizumab clinical development programme-all in GEMINI 1, GEMINI 2 and GEMINI LTS (see online supplementary table S7). No deaths were reported in the 13 phase 1 and phase 2 studies. Detailed accounts of the deaths during GEMINI 1 and GEMINI 2 have been previously reported. ${ }^{4}$ All patients with sepsis-related deaths had worsening of underlying disease, significant comorbidities and complicated hospital courses that included surgeries in two cases, all of which confound the assessment of relationship to study drug. The two deaths due to suicide occurred in patients with long durations of $\mathrm{CD}$ who were being treated for depression.

\section{DISCUSSION}

Integrated safety data for $>4000$ PYs of vedolizumab exposure in six clinical trials demonstrate that long-term vedolizumab treatment is well-tolerated with an acceptable safety profile in patients with moderately to severely active UC or CD. The safety profile of vedolizumab in the integrated patient population, which considerably extends the available safety data, was similar to that reported in the individual studies. ${ }^{4-8}$ Notably, in the year-long placebo-controlled GEMINI 1 and GEMINI 2 studies, dosing at every 4 weeks or at every 8 weeks yielded similar $\mathrm{AE}$ profiles. ${ }^{4}{ }^{5}$

The most frequently reported AEs were GI events and infections in patient populations with UC and CD. In general, when adjusted for exposure, AEs were reported more frequently with placebo (419.4/100 PYs) than with vedolizumab (247.8/100 PYs). These exposure-adjusted incidence rates provide an estimate of the number of patients who would experience the event of interest if 100 patients were treated for 1 year. Based upon this approach, a patient who experienced the same $\mathrm{AE}$ multiple times was counted only once. Given the longer average duration of exposure to vedolizumab, it is possible that a single patient may have experienced the same event more times with vedolizumab than with placebo. The disproportionate PYs of follow-up with vedolizumab compared with placebo-a limitation of the present analyses-and the low numbers of observed events warrant the need for further investigation. Although the placebo group does not allow for direct comparisons, especially for 


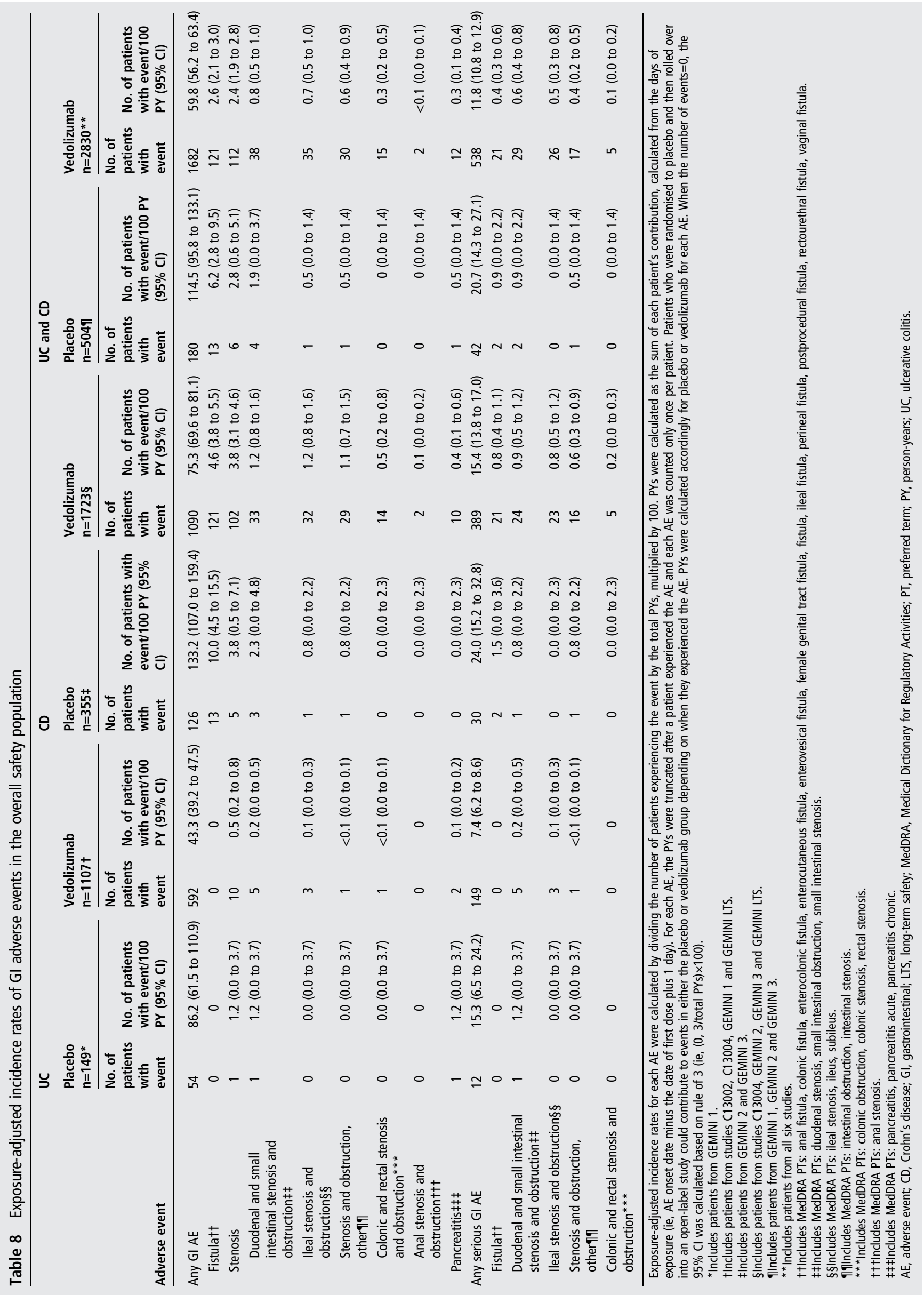

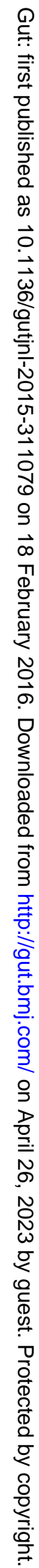


events occurring beyond 6 months of exposure, incidence rates for vedolizumab-treated patients can be compared with that observed in the HealthCore Integrated Research Database (HIRD), one of the largest commercially insured populations in the USA. The HIRD provides estimates of background incidence rates of AEs from 14733 commercially insured US patients with moderately to severely active IBD. ${ }^{17}$ However, as real-world disease management often differs from that in clinical trials, comparison of outcomes to the HIRD should be interpreted with caution.

Importantly, we did not observe an overall increase in the risk of infection or serious infection with vedolizumab exposure. The overall incidence rates of infection and serious infection with vedolizumab were 63.5/100 PYs and 4.3/100 PYs, respectively (vs $82.9 / 100$ PYs and 3.8/100 PYs for placebo). For the majority of infections and serious infections, the $95 \%$ CIs for placebo events overlapped with the point estimates for vedolizumab events. No indication for serious opportunistic infections, such as disseminated $\mathrm{TB}$, systemic candidiasis, disseminated herpes zoster, extraintestinal cytomegalovirus (CMV) infections or Pneumocystis pneumonia, was observed. Listeria meningitis was reported in one patient with CD. There were three cases of pulmonary $\mathrm{TB}$ with no extrapulmonary manifestations in patients from countries with higher endemic rates of TB relative to the USA and western Europe. ${ }^{18}$ In a pooled analysis of GEMINI 1 and GEMINI 2 data, the infection profiles in patients who received vedolizumab were similar with or without concomitant corticosteroids and/or immunosuppressives. ${ }^{19}$ It should be noted that patients receiving placebo may have more active disease and a greater propensity for intestinal infections, which could confound the reported incidence rates. However, the low incidence of infections with vedolizumab treatment is promising and consistent with what has been reported in HIRD (eg, for clostridial infections, we report 0.7/100 PYs (95\% CI 0.5 to 1.0 ) while the HIRD reports 3.1/1000 PYs (95\% CI 2.1 to 4.5 ) for Clostridium difficile diarrhoea/colitis). ${ }^{17}$

These observations, which are consistent with vedolizumab's gut-selective mechanism of action, have important clinical implications. Morbidity and mortality from common infections such as community-acquired pneumonia and opportunistic infection are concerns with existing immunosuppressive IBD therapies. ${ }^{20-22}$ Epidemiological studies to evaluate whether vedolizumab may represent a safer alternative are needed.

Enteric infections were infrequent in vedolizumab-exposed patients. Apart from gastroenteritis and abscess, all other enteric infections (eg, clostridial, CMV, streptococcal, appendicitis, diarrhoea, enterocolitis, diverticulitis) were reported with incidence rates of $\leq 0.8 / 100$ PYs each. All cases of clostridial or CMV infection occurred in patients exposed to vedolizumab. One patient had a streptococcal infection with placebo exposure versus 36 vedolizumab-exposed patients. An increased risk of some GI infections is plausible based on the gut-selective mechanism of action for vedolizumab. To further investigate this potential risk, a prospective patient registry has been initiated to evaluate the risk of enteric and other infections.

The development of PML, an often fatal complication of JCV infection, is a well-established risk of prolonged treatment with natalizumab, a monoclonal antibody directed to the $\alpha_{4}$ integrin. $^{23}$ In natalizumab clinical trials representing almost 3000 patients with 18 months of exposure, there were three cases of PML that occurred with a mean latency of 18 months. ${ }^{24}$ As of June 2015, 566 cases of PML had been confirmed among over 138800 patients exposed to postmarket natalizumab from which PML risk estimates were identified. ${ }^{25}$ Applying these risk estimates to the database of all vedolizumab trials, an average of at least six PML events would have been expected if PML risk with vedolizumab were the same as for natalizumab. In contrast, no cases of PML were observed during vedolizumab clinical development in the context of a rigorous risk monitoring programme. These data suggest that any PML risk with vedolizumab, if present, is likely to be significantly lower than for natalizumab.

Collectively, these data indicate that vedolizumab treatment is not associated with increased risk of serious and opportunistic infections. Using a Cox proportional hazards model, the factors independently associated with serious infection in patients with UC and CD were younger age, on-study narcotic analgesic use and on-study corticosteroid use. When analysed separately, the same risk factors were identified in patients with $\mathrm{CD}$. In contrast, prior failure with anti-TNFs was an independent risk factor for serious infection in patients with UC, while younger age and concomitant corticosteroid use were not identified in the UC population alone. These data are in agreement with a study by Lichtenstein $e t a l^{26}$ which reported that on-study narcotic analgesic use (HR, $1.98 ; 95 \%$ CI 1.44 to $2.73 ; \mathrm{p}<0.001)$ and prednisone therapy (HR, 1.57; 95\% CI 1.17 to 2.10; $\mathrm{p}=0.002)$ were independently associated with serious infection in patients with CD. In contrast to our model, Lichtenstein et $a l^{26}$ identified disease activity and infliximab treatment as independent predictors of serious infection. Of note, older age (HR, 1.08; 95\% CI 1.07 to 1.09 ; $\mathrm{p}<0.001$ ) was associated with increased mortality risk in their study. ${ }^{26}$

The potential for IRRs is a known risk with biological therapeutics, including monoclonal antibodies such as vedolizumab. ${ }^{21}$ Across the six vedolizumab clinical studies, $\leq 5 \%$ of patients experienced an IRR, the majority of which were mild or moderate in intensity. Overall immunogenicity rates with long-term exposure were low, and there was no apparent association between AVAs and IRRs. As with other monoclonal antibodies, treatment with vedolizumab is associated with AVAs. Rate of antibody formation can be reduced by coadministration of immunosuppressives. For individual patients, the balance between safety and protection against immunogenicity for longterm durability of remission should be evaluated.

Some treatments for IBD increase the risk of cancer. Patients treated with purine antimetabolites have a well-established increased risk of skin cancer and lymphoma. ${ }^{27}$ We observed no noticeable relationship between the development of malignancy and age, sex, type of malignancy or duration of vedolizumab exposure. The occurrence of four cases of colon cancer out of a population of $>2800$ patients ( $0.1 / 100$ PYs) is consistent with published data regarding the incidence of this complication in patients with IBD and is less than what was observed in HIRD (2.1/1000 PYs; 95\% CI 1.3 to 3.2). ${ }^{17}{ }^{28}$ Notably, the incidence of non-melanoma skin cancer in vedolizumab-exposed patients was not greater than in patients who received placebo. Non-melanoma skin cancer is the most common malignancy related to immunosuppression ${ }^{29}$ and can be a useful bellwether for this risk. Further, risk of non-melanoma skin cancer is increased when patients are treated with thiopurines. ${ }^{27}$ All vedolizumab-exposed patients diagnosed with skin cancer had a history of azathioprine therapy, and two continued azathioprine use on study. While vedolizumab does not have a known effect on impairment of $\mathrm{T}$ cell mediated cancer surveillance in extraintestinal organs, prospective studies are required to fully evaluate the risk of malignancy in patients receiving vedolizumab long-term.

In addition to infection, cancer and IRRs, the suppression of systemic immunity by anti-TNFs has been associated with 
autoimmune complications including psoriatic lesions, demyelination and drug-induced lupus. ${ }^{21}{ }^{30-32}$ In a recent review of the US Food and Drug Administration Adverse Event Reporting System (FAERS) database, anti-TNF exposure was associated with a psoriasis-proportional reporting ratio of 9.24 compared with drugs implicated in the development of psoriasis. ${ }^{33}$ Of all neurological AEs with anti-TNFs reported to the FAERS, 153 reports $(19.8 \%)$ were central nervous system and/or spinal cord demyelination. ${ }^{34}$ Lupus-like syndrome is estimated to occur in $0.2-0.4 \%$ of patients treated with anti-TNFs, although some cases may be attributed to unmasking of latent systemic lupus erythematosus rather than true lupus-like syndrome. ${ }^{21}$ In contrast, no signal for these uncommon anti-TNF-related complications was observed with vedolizumab exposure, although there was one case of cutaneous lupus. Liver dysfunction has been associated with normal IBD progression and immunosuppressive use. $^{2135}$ Although a low incidence of hepatobiliary events was observed among vedolizumab-treated patients only, further study is necessary to determine whether these complications are drug related. Indeed, in the clinical development programme overall, the rates of autoimmune and hepatobiliary events of any type were exceedingly low.

In conclusion, the integrated clinical trial data set of 2932 patients with moderately to severely active UC or CD presented herein provides evidence that there are no significant safety concerns associated with vedolizumab treatment. Vedolizumab offers a targeted, gut-selective mechanism of action without any clear increase in the risk of serious systemic opportunistic infections or other common complications for a set of diseases that typically require lifelong therapy.

\author{
Author affiliations \\ ${ }^{1}$ Division of Gastroenterology, Icahn School of Medicine at Mount Sinai Hospital, \\ New York, New York, USA \\ ${ }^{2}$ Division of Gastroenterology, Katholieke Universiteit and University Hospital \\ Gasthuisberg, Leuven, Belgium \\ ${ }^{3}$ Division of Gastroenterology, University of California San Diego and UC San Diego \\ Health System, La Jolla, California, USA \\ ${ }^{4}$ Department of Gastroenterology, Istituto Clinico Humanitas, Milan, Italy \\ ${ }^{5}$ Department of Gastroenterology, Academic Medical Center, Amsterdam, The \\ Netherlands \\ ${ }^{6}$ Department of Medicine, University of Calgary, Calgary, Alberta, Canada \\ ${ }^{7}$ Division of Gastroenterology and Hepatology, Mayo Clinic, Rochester, Minnesota, \\ USA \\ ${ }^{8}$ Takeda Pharmaceuticals International Co., Cambridge, Massachusetts, USA \\ ${ }^{9}$ Takeda Global Research and Development Centre (Europe) Ltd., London, UK \\ ${ }^{10}$ Department of Medicine, Robarts Clinical Trials, Robarts Research Institute, \\ University of Western Ontario, London, Ontario, Canada
}

Contributors $A P, B G F, J-F C, B A$ and $C M$ contributed to the design of the vedolizumab integrated analyses and drafting of the manuscript. All authors critically reviewed and revised the manuscript for important intellectual content and approved the final version of the manuscript before submission.

Funding The clinical studies were funded by Millennium Pharmaceuticals (d/b/a Takeda Pharmaceuticals International). Writing assistance: medical writing assistance was provided by inVentiv Medical Communications and supported by Takeda Pharmaceuticals International.

Competing interests J-FC has served as consultant, advisory board member or speaker for AbbVie, ABScience, Amgen, Bristol-Myers Squibb, Celltrion, Danone, Ferring, Genentech, Giuliani SPA, Given Imaging, Janssen, Immune Pharmaceuticals, Medlmmune, Merck \& Co, Millennium Pharmaceuticals, Neovacs, Nutrition Science Partners, Pfizer, Prometheus Laboratories, Protagonist, Receptos, Sanofi, Schering Plough Corporation, Second Genome, Shire, Takeda, Teva Pharmaceuticals, Tigenix, UCB Pharma, Vertex, Dr August Wolff GmbH \& Co. BES has served as a consultant for Abbott Immunology, AbbVie, Amgen, Astellas Pharma Global Development, AstraZeneca, Avaxia Biologics, Baxter Healthcare, Bracco Diagnostics, Bristol-Myers Squibb, Creative Educational Concepts, Curatio CME Institute/Axis Healthcare Communications, LLC, Dainippon Sumitomo Pharma, Dyax Corp, Elan Pharmaceuticals, Emmi Solutions, GlaxoSmithKline, Glaxo Wellcome, IMEDEX,
Immune Pharmaceuticals, Janssen Biotech, Kyowa Hakko Kirin Pharma, Luitpold Pharmaceuticals, Mechanisms in Medicine, Pfizer, Prometheus Laboratories, PureTech Ventures, Sigmoid Pharma, Takeda Pharmaceuticals International Company, and Teva Pharmaceutical Industries; received financial support for research from Prometheus Laboratories, Pfizer, Janssen Biotech, Bristol-Myers Squibb, AbbVie, Medlmmune; served as a speaker for Creative Educational Concepts; and is a shareholder of Avaxia Biologics. PR has served as a consultant for Bristol-Myers Squibb, Merck \& Co, Abbott, Millennium/Takeda, Neovacs, Actogenics, Amgen, Pfizer, Falk Pharma, Tillotts, UCB Pharma; has received Grant/Research Support from Abbott, J\&J, Genentech; and has received speaker fees from Centocor, Pfizer. WS has received financial support for research from Janssen, AbbVie, Pfizer, Amgen, Genentech; has received lecture fees from AbbVie, Takeda; and has served as a consultant to Janssen, AbbVie, Pfizer, Amgen, Genentech, Takeda. SD has served as a consultant, advisory board member, or review panel member for MSD, Schering Plough Corp, Abbott Laboratories, UCB, Ferring Pharmaceuticals, Cellerix, Takeda Pharmaceutical Company, Nycomed, Actelion, AstraZeneca, Danone Research, Chiesi, Novo Nordisk, Cosmo Technologies, Celltrion, Pharmacosmos, Alfa Wassermann, Genentech, Grunenthal, Pfizer, Tigenix, Vifor, Johnson and Johnson. GD'H has served as a consultant for Janssen Biologics, Takeda, Boehringer Ingelheim, Galapagos, Tillotts, Receptos, Salix, Setpoint, Versant, Mitsubishi, Prometheus; has received speaker fees from Takeda, Falk Pharma, Abbvie; and has served on an advisory board for GlaxoSmithKline, TEVA, Shire Pharmaceuticals. RP has served as a consultant, advisory board member or speaker for Abbott, Biogen/ IDEC, Axcan Pharma, Bristol-Myers Squibb, Centocor, Chemocentryx, Ferring Pharmaceuticals, Genentech, Lippincott Williams \& Wilkins, Medscape, Osiris Therapeutics, Novartis Pharmaceuticals, Genentech, Elan Pharmaceuticals, UCB; and has received research support from Abbott, UCB. EVL has received financial support for research from AbbVie, Janssen, UCB, Takeda, Pfizer, GlaxoSmithKline, Amgen, Bristol-Myers Squibb, Genentech, Robarts Clinical Trials, Gilead, Receptos; and has served as a consultant for AbbVie, Janssen, UCB, Takeda, Immune Pharmaceuticals, Celgene, Medlmmune, Theradiag, Genentech, Seres Health, Sun Pharmaceuticals, Bristol-Myers Squibb. SS, IF, AP, CM are employees of Takeda Pharmaceuticals International, Cambridge, Massachusetts, USA. BA is an employee of Takeda Development Centre Europe, London, UK. BGF has received financial support for research from Abbott/AbbVie, Amgen, AstraZeneca, Bristol-Myers Squibb (BMS), Janssen Biotech (Centocor), JnJ/Janssen, Roche/Genentech, Millennium, Pfizer, Receptos, Santarus, Sanofi, Tillotts, UCB Pharma; has received lecture fees from Abbott/AbbVie, JnJ/Janssen, Takeda, Warner-Chilcott, UCB Pharma; served as a consultant for Abbott/AbbVie, Actogenix, Albireo Pharma, Amgen, AstraZeneca, Avaxia Biologics, Avir Pharma, Axcan, Baxter Healthcare, Biogen Idec, Boehringer-Ingelheim, Bristol-Myers Squibb, Calypso Biotech, Celgene, Elan/Biogen, EnGene, Ferring Pharma, Roche/Genentech, GiCare Pharma, Gilead, Given Imaging, GSK, Ironwood Pharma, Janssen Biotech (Centocor), InJ/Janssen, Kyowa Hakko Kirin, Lexicon, Lilly, Merck, Millennium, Nektar, Novo Nordisk, Pfizer, Prometheus Therapeutics and Diagnostics, Protagonist, Receptos, Salix Pharma, Serono, Shire, Sigmoid Pharma, Synergy Pharma, Takeda, Teva Pharma, TiGenix, Tillotts, UCB Pharma, Vertex Pharma, Warner-Chilcott, Wyeth, Zealand, Zyngenia; has served on advisory boards for Abbott/AbbVie, Amgen, AstraZeneca, Avaxia Biologics, Bristol-Myers Squibb, Celgene, Centocor, Elan/Biogen, Ferring, JnJ/Janssen, Merck, Novartis, Novo Nordisk, Pfizer, Prometheus Laboratories, Protagonist, Salix Pharma, Takeda, Teva, TiGenix, Tillotts Pharma AG, UCB Pharma; and holds a directorship as CEO and Senior Scientific Director, Robarts Clinical Trials, Western University, London, Ontario.

Provenance and peer review Not commissioned; externally peer reviewed.

Open Access This is an Open Access article distributed in accordance with the Creative Commons Attribution Non Commercial (CC BY-NC 4.0) license, which permits others to distribute, remix, adapt, build upon this work non-commercially, and license their derivative works on different terms, provided the original work is properly cited and the use is non-commercial. See: http://creativecommons.org/ licenses/by-nc/4.0/

\section{REFERENCES}

1 Mosli MH, Rivera-Nieves J, Feagan BG. T-cell trafficking and anti-adhesion strategies in inflammatory bowel disease: current and future prospects. Drugs 2014;74:297-311.

2 Soler D, Chapman T, Yang LL, et al. The binding specificity and selective antagonism of vedolizumab, an anti- $\alpha 4 \beta 7$ integrin therapeutic antibody in development for inflammatory bowel diseases. J Pharmacol Exp Ther 2009;330:864-75.

3 Garnock-Jones KP. Vedolizumab: a review of its use in adult patients with moderately to severely active ulcerative colitis or Crohn's disease. BioDrugs 2015;29:57-67.

4 Feagan BG, Rutgeerts $P$, Sands BE, et al. Vedolizumab as induction and maintenance therapy for ulcerative colitis. N Engl J Med 2013;369:699-710.

5 Sandborn WJ, Feagan BG, Rutgeerts $P$, et al. Vedolizumab as induction and maintenance therapy for Crohn's disease. N Engl J Med 2013;369:711-21. 
6 Sands $B E$, Feagan $B G$, Rutgeerts $P$, et al. Effects of vedolizumab induction therapy for patients with Crohn's disease in whom tumor necrosis factor antagonist treatment failed. Gastroenterology 2014;147:618-27.e3.

7 Parikh A, Fox I, Leach T, et al. Long-term clinical experience with vedolizumab in patients with inflammatory bowel disease. Inflamm Bowel Dis 2013;19:1691-9.

8 Parikh A, Leach $\mathrm{T}$, Wyant $\mathrm{T}$, et al. Vedolizumab for the treatment of active ulcerative colitis: a randomized controlled phase 2 dose-ranging study. Inflamm Bowel Dis 2012;18:1470-9.

9 Feagan BG, Kaser A, Smyth M, et al. Long-term efficacy of vedolizumab therapy for ulcerative colitis. United Eur Gastroenterol J 2014;2(Suppl 1):A66.

10 Hanauer SB, Rutgeerts $P$, Xu J, et al. Long-term efficacy of vedolizumab therapy for Crohn's disease. United Eur Gastroenterol J 2014;2(Suppl 1):A66.

11 Rosario M, Dirks NL, Gastonguay MR, et al. Population pharmacokineticspharmacodynamics of vedolizumab in patients with ulcerative colitis and Crohn's disease. Aliment Pharmacol Ther 2015:42:188-202.

12 Brown EG, Wood L, Wood $\mathrm{S}$. The medical dictionary for regulatory activities (MedDRA). Drug Saf 1999;20:109-17.

13 Wyant T, Estevam J, Yang L, et al. Development and validation of receptor occupancy pharmacodynamic assays used in the clinical development of the monoclonal antibody vedolizumab. Cytometry B Clin Cytom 2015 doi:10.1002/cyto.b.21236.

14 Clifford D, McAuliffe M, Stephens K, et al. Risk assessment and minimization for progressive multifocal leukoencephalopathy (PML) (RAMP): a program to assess the potential early signs and symptoms of PML during clinical development of vedolizumab. Am J Gastroenterol 2013;108(Suppl 1):S502.

15 Rosario M, Fox I, Milch C, et al. Pharmacokinetic/pharmacodynamic relationship and immunogenicity of vedolizumab in adults with inflammatory bowel disease: additional results from GEMINI 1 and 2. Inflamm Bowel Dis 2013;19(Suppl 1): Abstract $p-140$

16 Sands BE, Cohen $\mathrm{R}$, Isaacs $\mathrm{K}$, et al. Infusion-related reactions with vedolizumab treatment in patients with UC or CD during the GEMINI 1 and GEMINI 2 clinical trials. J Crohns Colitis 2015;9(Suppl 1):S392-3.

17 McAuliffe ME, Lanes $S$, Leach $T$, et al. Occurrence of adverse events among patients with inflammatory bowel disease in the HealthCore Integrated Research Database. Curr Med Res Opin 2015;31:1655-64.

18 World Health Organization (WHO). Global tuberculosis report 2014. Geneva, Switzerland: WHO Press, 2014

19 Colombel JF, Siegel CA, Abhyankar B, et al. Safety of vedolizumab alone or with concomitant corticosteroids and/or immunosuppressives in patients with ulcerative colitis or Crohn's disease. United Eur Gastroenterol J 2014;2(Suppl 1): A82.
20 Dave $M$, Purohit $\mathrm{T}$, Razonable $\mathrm{R}$, et al. Opportunistic infections due to inflammatory bowel disease therapy. Inflamm Bowel Dis 2014;20:196-212.

21 McLean LP, Cross RK. Adverse events in IBD: to stop or continue immune suppressant and biologic treatment. Expert Rev Gastroenterol Hepatol 2014;8:223-40.

22 Ford AC, Peyrin-Biroulet L. Opportunistic infections with anti-tumor necrosis factor-alpha therapy in inflammatory bowel disease: meta-analysis of randomized controlled trials. Am J Gastroenterol 2013;108:1268-76.

23 Sørensen PS, Bertolotto A, Edan G, et al. Risk stratification for progressive multifocal leukoencephalopathy in patients treated with natalizumab. Mult Scler 2012;18:143-52.

24 Biogen. Tysabri (natalizumab) [package insert]. Cambridge, MA: Biogen Idec Inc., 2013.

25 Biogen. US-TYSABRI-update. June 2015 ed. MedInfo: Biogen, 2015.

26 Lichtenstein GR, Feagan BG, Cohen RD, et al. Serious infection and mortality in patients with Crohn's disease: more than 5 years of follow-up in the TREAT registry. Am J Gastroenterol 2012;107:1409-22.

27 Magro F, Peyrin-Biroulet L, Sokol H, et al. Extra-intestinal malignancies in inflammatory bowel disease: results of the 3rd ECCO Pathogenesis Scientific Workshop (III). J Crohns Colitis 2014:8:31-44.

28 Kappelman MD, Farkas DK, Long MD, et al. Risk of cancer in patients with inflammatory bowel diseases: a nationwide population-based cohort study with 30 years of follow-up evaluation. Clin Gastroenterol Hepatol 2014;12:265-73.e1.

29 Mulholland MW, Doherty GM. Complications in surgery. Philadelphia: Lippincott Williams \& Wilkins, 2006.

30 Baumgart DC, Grittner U, Steingräber A, et al. Frequency, phenotype, outcome, and therapeutic impact of skin reactions following initiation of adalimumab therapy: experience from a consecutive cohort of inflammatory bowel disease patients. Inflamm Bowel Dis 2011:17:2512-20.

31 Williams VL, Cohen PR. TNF alpha antagonist-induced lupus-like syndrome: report and review of the literature with implications for treatment with alternative TNF alpha antagonists. Int J Dermatol 2011;50:619-25.

32 Kaltsonoudis E, Voulgari PV, Konitsiotis $\mathrm{S}$, et al. Demyelination and other neurological adverse events after anti-TNF therapy. Autoimmun Rev 2014;13:54-8.

33 Kip KE, Swoger JM, Grandinetti LM, et al. Tumor necrosis factor alpha antagonist-associated psoriasis in inflammatory diseases: an analysis of the FDA adverse event reporting system. Inflamm Bowel Dis 2013;19:1164-72.

34 Deepak P, Stobaugh DJ, Sherid M, et al. Neurological events with tumour necrosis factor alpha inhibitors reported to the Food and Drug Administration Adverse Event Reporting System. Aliment Pharmacol Ther 2013:38:388-96.

35 Nahon S, Cadranel JF, Chazouilleres 0, et al. Liver and inflammatory bowel disease. Gastroenterol Clin Biol 2009:33:370-81. 